\title{
3D dose delivery verification using repeated cone- beam imaging and EPID dosimetry for stereotactic body radiotherapy of non-small cell lung cancer
}

Citation for published version (APA):

van Elmpt, W., Petit, S., De Ruysscher, D., Lambin, P., \& Dekker, A. (2010). 3D dose delivery verification using repeated cone-beam imaging and EPID dosimetry for stereotactic body radiotherapy of non-small cell lung cancer. Radiotherapy and Oncology, 94(2), 188-194.

https://doi.org/10.1016/j.radonc.2009.12.024

Document status and date:

Published: 01/02/2010

DOI:

10.1016/j.radonc.2009.12.024

Document Version:

Publisher's PDF, also known as Version of record

\section{Document license:}

Taverne

Please check the document version of this publication:

- A submitted manuscript is the version of the article upon submission and before peer-review. There can be important differences between the submitted version and the official published version of record.

People interested in the research are advised to contact the author for the final version of the publication, or visit the DOI to the publisher's website.

- The final author version and the galley proof are versions of the publication after peer review.

- The final published version features the final layout of the paper including the volume, issue and page numbers.

Link to publication

\footnotetext{
General rights rights.

- You may freely distribute the URL identifying the publication in the public portal. please follow below link for the End User Agreement:

www.umlib.nl/taverne-license

Take down policy

If you believe that this document breaches copyright please contact us at:

repository@maastrichtuniversity.nl

providing details and we will investigate your claim.
}

Copyright and moral rights for the publications made accessible in the public portal are retained by the authors and/or other copyright owners and it is a condition of accessing publications that users recognise and abide by the legal requirements associated with these

- Users may download and print one copy of any publication from the public portal for the purpose of private study or research.

- You may not further distribute the material or use it for any profit-making activity or commercial gain

If the publication is distributed under the terms of Article $25 \mathrm{fa}$ of the Dutch Copyright Act, indicated by the "Taverne" license above, 
Portal imaging

\title{
3D dose delivery verification using repeated cone-beam imaging and EPID dosimetry for stereotactic body radiotherapy of non-small cell lung cancer
}

\author{
Wouter van Elmpt ${ }^{*, 1}$, Steven Petit ${ }^{1}$, Dirk De Ruysscher, Philippe Lambin, André Dekker \\ Department of Radiation Oncology (MAASTRO), Maastricht University Medical Centre, The Netherlands
}

\section{A R T I C L E I N F O}

\section{Article history:}

Received 19 October 2009

Received in revised form 11 December 2009

Accepted 20 December 2009

Available online 18 January 2010

\section{Keywords:}

Dose reconstruction

Treatment verification

Cone-beam imaging

SBRT

Non-small cell lung cancer

Dose verification

Lung cancer

\begin{abstract}
A B S T R A C T
Purpose: To implement a 3D dose verification procedure, based on in-room cone-beam CT imaging and portal dosimetry, for lung cancer patients treated with stereotactic body radiotherapy (SBRT).

Materials and methods: MV cone-beam CT scans were made for patient positioning and calibrated for dose calculation purposes. Prior to treatment, the treatment fields were captured using a calibrated electronic portal imaging device (EPID). A Monte Carlo dose reconstruction model was used to estimate the 3D dose delivered to the patient inside the cone-beam CT images. The planned and delivered dose distributions were compared for 4 patients and 10 treatment fractions using dose-volume histograms and gamma analysis.

Results: The gamma analysis showed a good agreement between the planned and delivered dose distributions for patients without changes in anatomy. The delivered mean dose per fraction inside the target volume deviated on average $1.1 \pm 1.4 \%$ from the planned dose. For the critical organs, only minor differences were observed between the reconstructed and planned dose.

Conclusions: A method was presented that allows verification of the dose delivered in 3D for lung cancer patients treated with SBRT. The procedure is independent of the treatment planning system and uses inroom MV cone-beam CT imaging and portal dosimetry.
\end{abstract}

(c) 2009 Elsevier Ireland Ltd. All rights reserved. Radiotherapy and Oncology 94 (2010) 188-194
Accurate dose delivery is crucial for a successful radiotherapy treatment. Stereotactic body radiotherapy (SBRT) is a frequently used treatment for stage I/II non-small cell lung cancer patients with a peripheral primary tumour inside the lung and no nodal involvement. The treatment is hypo-fractionated in typically 3-8 delivery sessions with high dose levels to small regions. Therefore geometrical and dosimetrical precision must be high. Due to breathing motion, small target volumes, steep dose gradients and inhomogeneous densities in the thoracic region, accurate treatment delivery is not always guaranteed $[1,2]$. Hence, dose delivery verification is a prerequisite to assure correct treatment planning and delivery for these patients.

Over the past years multiple solutions have been presented for image-guided radiotherapy (IGRT) to improve patient set-up [3,4]. For dosimetric verification, electronic portal imaging devices (EPIDs) are used more and more to verify the dose delivery prior and during (in vivo) treatment [5-9].

\footnotetext{
* Corresponding author. Address: Department of Radiation Oncology (MAASTRO clinic), GROW - School for Oncology and Developmental Biology, Maastricht University Medical Centre, Dr. Tanslaan 12, NL-6229 ET Maastricht, The Netherlands.

E-mail address: wouter.vanelmpt@maastro.nl (W. van Elmpt).

1 Both authors contributed equally to this work.
}

A combination of the IGRT procedures and the dosimetry measurements will yield a more comprehensive verification than both approaches separately. Therefore we developed a method that is able to reconstruct the dose delivered to the patient based on IGRT procedures and dose measurements. The actual delivered energy fluence of the treatment machine is measured using the portal imager prior to treatment as part of a separate patient-specific QA program [10]. At the time of treatment the patient anatomy is imaged with the current in-room capabilities. We have used MV cone-beam CT (MVCBCT) imaging currently available on our treatment machine. The delivered dose in the patient anatomy is then reconstructed in this MVCBCT scan using a Monte Carlo code that uses the delivered energy fluence as input. All steps are totally independent of the treatment planning system and this procedure provides $3 \mathrm{D}$ dose verification in the patient anatomy during a treatment fraction.

The aim of this study was to develop this method and show that it is feasible for stereotactically irradiated non-small cell lung cancer patients. This method could be used in a clinical routine session without additional measurements or treatment and patient time which is a requirement in high-throughput radiotherapy departments. The method is suitable as a tool for in vivo QA. In addition, with this method the delivered 3D dose distribution is calculated, which is a prerequisite for dose-guided plan adaptation and adaptive radiotherapy (ART). 


\section{Materials and methods}

\section{Patient characteristics and planning strategy}

For this study we retrospectively selected at random four nonsmall cell lung cancer patients treated in our clinic with SBRT between 2008 and 2009. The available cone-beam CT scans for these patients were retrieved from our database, but not for every fraction the cone-beam CT scans could be used because raw projection data were not available anymore. Treatment plans were created with our clinically used treatment planning system (XiO 4.3.4, CMS, St. Louis, USA) using the advanced superposition algorithm with inhomogeneity corrections applied on a grid size of $3 \times 3 \times 3 \mathrm{~mm}^{3}$. This type of dose calculations algorithm is suitable for calculating dose distributions for small fields and in regions with density gradients [1].

For these patients a 4D CT scan was acquired and the mid-ventilation phase was used for delineation and treatment planning. The amplitude of tumour motion is derived from the 4D CT scan and incorporated as a patient-specific margin in the internal target volume (ITV). The clinical tumour volume (CTV) was equal to the gross tumour volume (GTV) and the ITV to planning target volume (PTV) margin was fixed at $3 \mathrm{~mm}$.

The treatment plan typically consists of 8 treatment fields and was based on the ROSEL study criteria [11]. This study allows for 3 fractionation schedules: $3 \times 18 \mathrm{~Gy}, 5 \times 12 \mathrm{~Gy}$ and $8 \times 7.5 \mathrm{~Gy}$ depending on tumour size and location. Energies of both 6 and $10 \mathrm{MV}$ photons were allowed and wedges were applied if necessary. The main planning objectives and constraints from the ROSEL study are that at least 95\% of the PTV must receive the prescribed dose. An underdosage of $10 \%$ to at maximum $1 \%$ of the PTV is allowed. The maximum PTV dose preferentially must be between $110 \%$ and $140 \%$ and the volume of both lungs, excluding the GTV, that receives more than $20 \mathrm{~Gy}\left(V_{20}\right)$ should be limited to $15 \%$.

\section{Workflow}

The 3D dose reconstruction procedure needs three components: (1) the patient anatomy, (2) the delivered energy fluence of the linear accelerator and (3) a dose calculation algorithm that calculates the delivered dose in the patient anatomy. These components will be described in the following sections.

\section{Cone-beam image acquisition}

Prior to treatment delivery, an image-guided radiotherapy procedure for patient set-up verification is performed. A mega-voltage cone-beam CT image is acquired (MVision, Siemens OCS, Concord, USA) using the standard clinical image acquisition settings and a total of 7 or 13 monitor units. The reconstructed images have a field-of-view of $27 \times 27 \times 27 \mathrm{~cm}^{3}$ at a voxel size of $1 \times 1 \times 1$ $\mathrm{mm}^{3}$. The cone-beam CT scan is registered to the mid-ventilation phase of the $4 \mathrm{D}$ planning $\mathrm{CT}$ scan using a rigid registration applying only translations (rotations are ignored because our treatment couch does not support all rotational degrees of freedom). The patients presented in this study were treated during the implementation phase of the IGRT procedure based on cone-beam CT imaging. Hence, we still performed a correction strategy based on conventional 2D portal imaging.

To use the cone-beam CT scan for dose calculation purposes, the pixel values of the CT scan should be converted to Hounsfield Units and subsequently to electron density values. Calibration methods for head-and-neck cancer patients where the FOV of the conebeam is large enough to capture the entire patient anatomy are already available $[12,13]$. For thoracic and abdominal treatment sites the FOV is generally too small and two options are available. One is increasing the FOV by using a lateral shift of the detector and acquiring a cone-beam over a 360 degree arc. This is not (yet) possible using our equipment. The second option is to use the planning CT scan to add the missing information and create a so-called conebeam+ image where the missing parts are added [14]. The correction of such a cone-beam+ dataset and the conversion to electron density requires specific corrections such as cupping corrections and a removal of the truncation artefacts caused by the limited field-of-view. The specific correction strategies and method we used are described elsewhere [15]. The cone-beam+ dataset is then used for dose calculation in the $3 \mathrm{D}$ dose reconstruction procedure.

\section{Dose delivery measurement and $3 D$ dose reconstruction}

A patient-specific QA and in vivo dosimetry program using EPID dosimetry is applied for all our patients treated with a curative intent. In our QA program, a dummy run of the actual treatment fields is delivered and the energy fluence of all treatment fields is measured using calibrated EPIDs [10]. This measurement is compared to an expected portal dose image and differences are quantified using the gamma evaluation. For this pre-treatment verification, more than $90 \%$ of the pixels in the image should have a gamma value smaller than 1 . The criteria of the gamma evaluation are a dose difference smaller than $3 \%$ or a distance-to-agreement smaller than $3 \mathrm{~mm}$.

The proposed 3D dose reconstruction procedure uses the measured energy fluence of the treatment beams as the input for a Monte Carlo based dose calculation. From the measured energy fluence a phase-space is derived which is used as the starting point for the dose calculation. The specifics and details of this method are described elsewhere [16-18].

\section{Comparison of planned and delivered dose distributions}

Comparison of dose distributions was made in two ways: dose distribution-based comparison and structure-based comparison. For the dose distribution-based comparison the planned and reconstructed dose distributions are quantitatively compared without considering the underlying organs. In this study, the three orthogonal dose planes (sagittal, coronal, and transversal) through the isocenter were compared. The isocenter coincided with the centre of the GTV for all patients. The planning and cone-beam+CT scans were rigidly registered and for the corresponding dose planes a 2D gamma analysis was performed. A distance-to-agreement of $3 \mathrm{~mm}$ and a dose criterion of $3 \%$ of the maximum dose were used. For the structure based comparison the PTV was copied from the planning CT scan to the conebeam $+C T$ scan. The critical organs and GTV were redelineated on the cone-beam+scans. Dose-volume histograms (DVHs) of the planned and reconstructed dose distributions were calculated and compared.

\section{Results}

An overview of the patient and tumour characteristics of the analysed patients is shown in Table 1

Cone-beam scans of patient 1 were acquired for four fractions. Fig. 1 shows a good agreement between the planned and reconstructed dose for each fraction on a transversal slice to the centre of the GTV. This is confirmed by the gamma image that only shows some minor deviations near the skin of the patient. The gamma statistics within the $20 \%, 50 \%$ and $80 \%$ iso-dose contours are presented in Table 2 and indicate a good agreement between the planned and reconstructed dose distributions. The GTVs were delineated in each cone-beam+ and the DVHs were calculated 

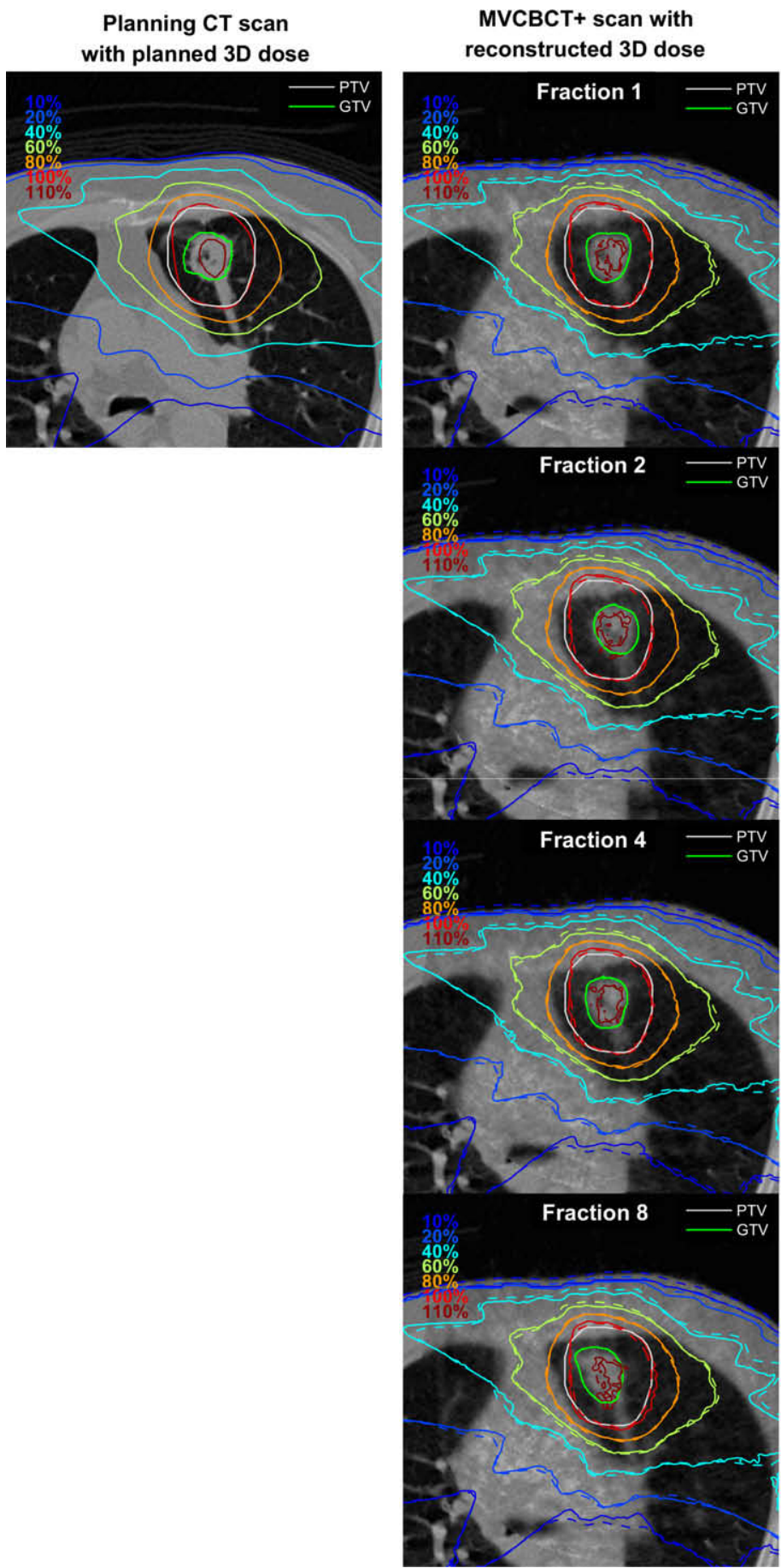

Gamma image (3\%/3mm) reconstructed vs. planned 3D dose
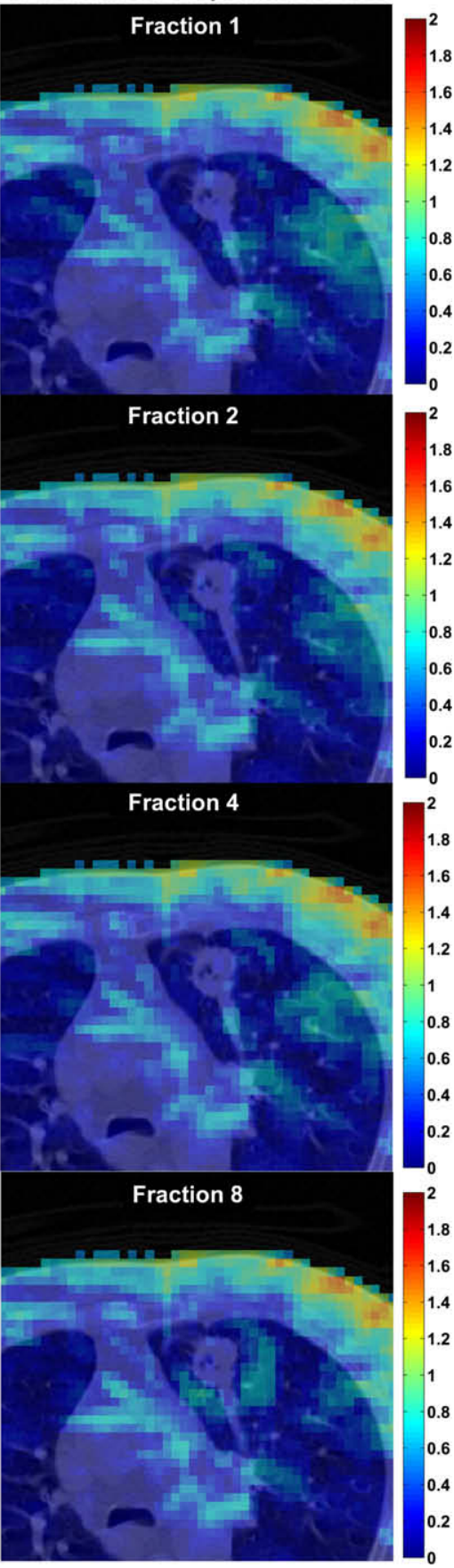

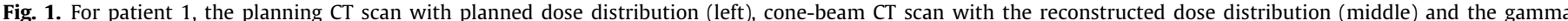
evaluation (right, $3 \% / 3 \mathrm{~mm}$ criteria) are shown.

Table 1

Patient characteristics.

\begin{tabular}{|c|c|c|c|c|}
\hline Patient No. & 1 & 2 & 3 & 4 \\
\hline Age & 66 & 72 & 87 & 62 \\
\hline Sex & $\mathrm{M}$ & M & $\mathrm{M}$ & $\mathrm{M}$ \\
\hline Stage & T1N0M0 & T2NOMO & T1N0M0 & T2NOMO \\
\hline Location & Left upper lobe & Left lower lobe & Left lower lobe & Right upper lobe \\
\hline Volume GTV $\left(\mathrm{cm}^{3}\right)$ & 13.4 & 24.5 & 6.8 & 11.4 \\
\hline Volume PTV $\left(\mathrm{cm}^{3}\right)$ & 99 & 155 & 90 & 99 \\
\hline Fractionation schedule & $8 \times 7.5 \mathrm{~Gy}$ & $3 \times 18 \mathrm{~Gy}$ & $8 \times 7.5 \mathrm{~Gy}$ & $8 \times 7.5 \mathrm{~Gy}$ \\
\hline Number of beams & $11(10 \mathrm{MV})$ & $9(6$ and $10 \mathrm{MV})$ & $8(10 \mathrm{MV})$ & $10(10 \mathrm{MV})$ \\
\hline Imaging data available of fraction & $1,2,4$ and 8 & 1,2 and 3 & 4 and 5 & 2 \\
\hline
\end{tabular}


Table 2

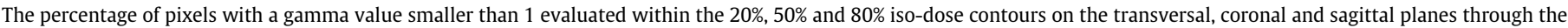
centre of the GTV.

\begin{tabular}{|c|c|c|c|c|c|c|c|c|c|c|}
\hline & \multirow[t]{2}{*}{ \% Iso-dose } & \multicolumn{3}{|c|}{ Transversal plane } & \multicolumn{3}{|c|}{ Coronal plane } & \multicolumn{3}{|c|}{ Sagittal plane } \\
\hline & & $20 \%$ & $50 \%$ & $80 \%$ & $20 \%$ & $50 \%$ & $80 \%$ & $20 \%$ & $50 \%$ & $80 \%$ \\
\hline \multirow[t]{4}{*}{ Patient 1} & Fraction 1 & 96 & 100 & 100 & 97 & 98 & 96 & 94 & 94 & 91 \\
\hline & Fraction 2 & 96 & 100 & 100 & 96 & 96 & 91 & 91 & 90 & 85 \\
\hline & Fraction 4 & 96 & 100 & 100 & 98 & 100 & 100 & 94 & 96 & 94 \\
\hline & Fraction 8 & 96 & 100 & 100 & 96 & 96 & 92 & 91 & 89 & 84 \\
\hline \multirow[t]{3}{*}{ Patient 2} & Fraction 1 & 95 & 97 & 99 & 96 & 93 & 94 & 90 & 92 & 86 \\
\hline & Fraction 2 & 97 & 95 & 94 & 100 & 100 & 99 & 95 & 91 & 88 \\
\hline & Fraction 3 & 97 & 95 & 95 & 95 & 92 & 87 & 92 & 85 & 78 \\
\hline \multirow[t]{2}{*}{ Patient 3} & Fraction 3 & 95 & 95 & 88 & 85 & 78 & 69 & 92 & 83 & 65 \\
\hline & Fraction 4 & 94 & 89 & 73 & 86 & 80 & 70 & 91 & 82 & 63 \\
\hline Patient 4 & Fraction 2 & 98 & 100 & 99 & 99 & 97 & 97 & 94 & 92 & 88 \\
\hline Average $\pm 1 \mathrm{SD}$ & & $96 \pm 1$ & $97 \pm 4$ & $95 \pm 9$ & $95 \pm 5$ & $93 \pm 8$ & $89 \pm 11$ & $93 \pm 2$ & $90 \pm 5$ & $82 \pm 11$ \\
\hline
\end{tabular}
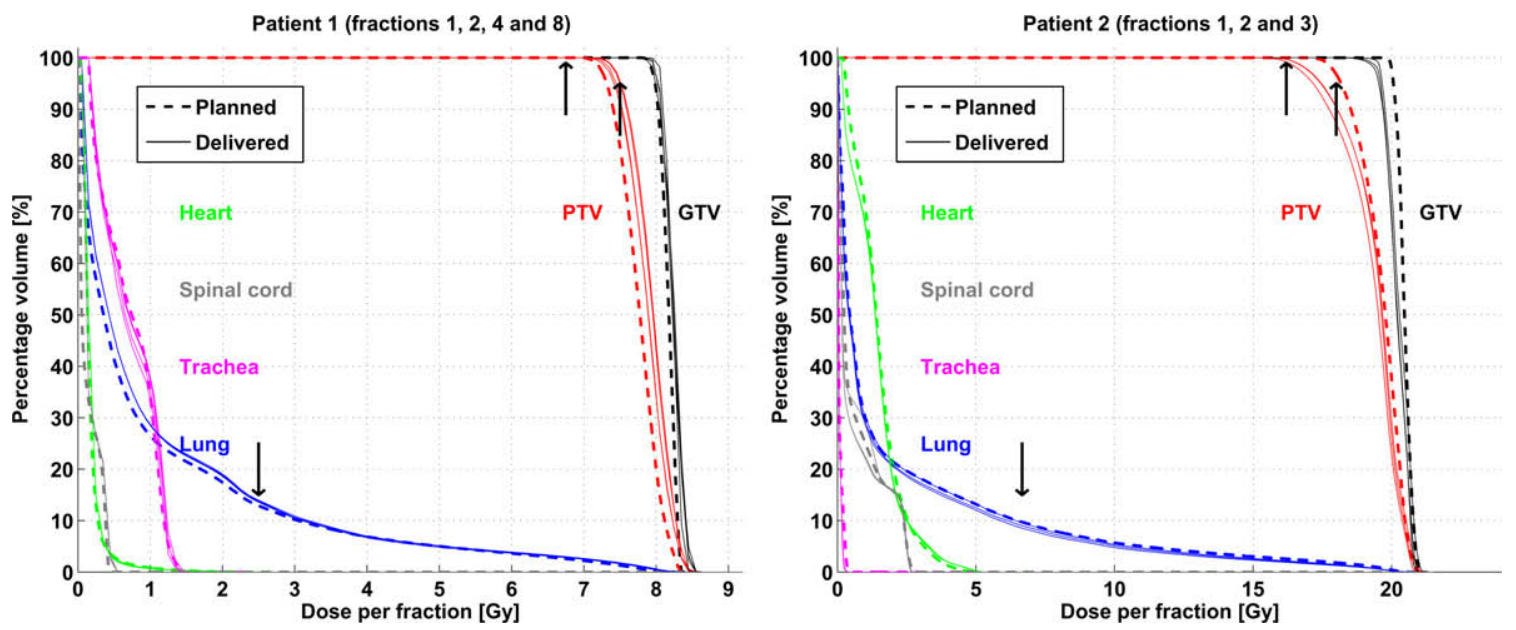

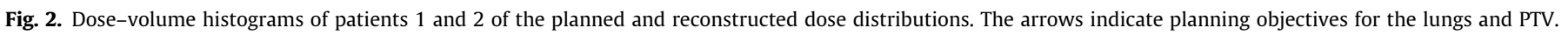

(Fig. 2). The maximum deviation from the planned mean GTV dose was only $0.4 \%$. For the planned dose distribution, less than $95 \%$ of the PTV received the prescribed dose, but this was accepted. However, the coverage of the PTV by the reconstructed dose distribution was higher and did fulfil the planning constraint. Both the planned and reconstructed dose distribution yielded a minimum dose to the PTV that was larger than $90 \%$ of the prescribed dose. The $V_{20}$ of the lungs was on average $14.1 \pm 0.2 \%$ compared to the planned $V_{20}$ of $12.9 \%$, but well below the allowed $15 \%$. The heart, spinal cord and trachea were comparable to the planned values and well below the maximum tolerated values (Table 3 ).

Patient 2 was treated with 3 fractions of $18 \mathrm{~Gy}$ and for each fraction a cone-beam CT scan was acquired. Comparison of the planned and reconstructed dose distribution yielded more than $90 \%$ of the pixels with gamma $<1$ within the $20 \%$ iso-dose contours in the three orthogonal slices. The reconstructed dose to the PTV was also lower and the PTV volume receiving the prescribed dose decreased from $97 \%$ to $87 \%$ compared to the planned dose, thereby violating the planning dose constraint (see Fig. 2 and Table 3). However, the DVH of the GTV revealed only a small underdosage of on average $1.3 \%$. The $V_{20}$ decreased from $9.8 \%$ to $9.1 \pm 0.5 \%$, which was well within the acceptable range.

For patient 3, cone-beam scans were available of the third and fourth fraction. The gamma analysis indicated a good agreement between the planned and reconstructed dose distributions within the $20 \%$ and $50 \%$ iso-dose contours. Within the $80 \%$ iso-dose contours the agreement was worse. This was mainly due to a base-line shift of the tumour compared to the 50\% exhale phase of the 4D CT, which was used for planning (Fig. 3). Especially at the fourth fraction the position of the GTV deviated considerably from the planning CT. It moved towards the edges of the high dose region, which lead to an underdosage of $1.5 \%$ in mean GTV dose compared to the third fraction. Irrespective of these deviations, the reconstructed dose distributions were well within the tolerated limits used for treatment planning. Normal tissue values are shown in Table 3.

Patient 4 was treated with $8 \times 7.5 \mathrm{~Gy}$ and only the cone-beam acquired at the second fraction could be retrieved from the database. The planned and reconstructed dose distributions agreed within the $20 \%$ iso-dose contour for more than $94 \%$ of the pixels. The reconstructed mean GTV dose was 1.3\% lower than planned but a larger part of the PTV was treated with more than the prescription dose of $7.5 \mathrm{~Gy}$ per fraction. Both the planned and reconstructed $V_{20}$ were larger than was allowed by the planning guidelines, but the difference was only $0.6 \%$.

\section{Discussion}

Treatment verification using 3D dose reconstruction based on information acquired in the treatment room is feasible and provides an independent verification of the treatment of stereotactic irradiated non-small cell lung cancer patients. We have analyzed four patient cases and ten treatment fractions and have shown that the delivered mean GTV dose corresponded within $1.1 \pm 1.4 \%$ from 
Table 3

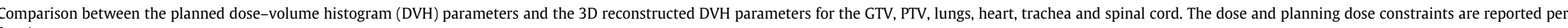
fraction.

\begin{tabular}{|c|c|c|c|c|c|c|c|c|c|c|c|}
\hline \multicolumn{2}{|c|}{ Planning dose objectives } & \multicolumn{3}{|l|}{ GTV } & \multicolumn{3}{|l|}{ PTV } & \multirow{2}{*}{$\begin{array}{l}\text { Lung (GTV excluded) } \\
V_{20}(\%)\end{array}$} & \multirow{2}{*}{$\begin{array}{l}\text { Heart } \\
\text { Maximum dose } \\
\text { to } 1 \mathrm{ml}(\mathrm{Gy}) \\
3 \text { fractions: } \\
8.7 \mathrm{~Gy} \\
8 \text { fractions: } \\
5.8 \mathrm{~Gy}\end{array}$} & \multirow{2}{*}{$\begin{array}{l}\text { Trachea } \\
\text { Maximum dose } \\
\text { to } 1 \mathrm{ml}(\mathrm{Gy}) \\
\\
3 \text { fractions: } \\
10.7 \mathrm{~Gy} \\
8 \text { fractions: } \\
8.2 \mathrm{~Gy}\end{array}$} & \multirow{2}{*}{$\begin{array}{l}\text { Spinal cord } \\
\begin{array}{l}\text { Maximum } \\
\text { dose (Gy) }\end{array} \\
3 \text { fractions } \\
7.3 \mathrm{~Gy} \\
8 \text { fractions: } \\
4.0 \mathrm{~Gy}\end{array}$} \\
\hline & & Volume $\left(\mathrm{cm}^{3}\right)$ & $\begin{array}{l}\text { Mean dose } \\
\text { (Gy (\% deviation)) }\end{array}$ & $\begin{array}{l}\text { Minimum dose } \\
\text { (Gy (\% deviation)) }\end{array}$ & $\begin{array}{l}D_{\max }(\% \text { of } \\
\left.D_{\text {prescribed }}\right) \\
>110 \% \\
\text { and }<140 \%\end{array}$ & $\begin{array}{l}V_{100 \% \text { of }} \\
\text { prescribed dose } \\
(\%) \\
>95 \%\end{array}$ & $\begin{array}{l}V_{90 \% \text { of }} \\
\text { prescribed dose } \\
(\%) \\
>99 \%\end{array}$ & & & & \\
\hline $\begin{array}{l}\text { Patient } 1 \\
\quad \text { ( } 8 \text { fractions) }\end{array}$ & $\begin{array}{l}\text { Planned } \\
\text { Fraction } 1 \\
\text { Fraction } 2 \\
\text { Fraction } 4 \\
\text { Fraction } 8 \\
\text { Average } \pm 1 S D\end{array}$ & $\begin{array}{l}12.2 \\
11.9 \\
13.5 \\
12.5 \\
11.8 \\
12.4 \pm 0.8\end{array}$ & $\begin{array}{l}8.1 \\
8.2(0.4) \\
8.2(0.4) \\
8.2(0.3) \\
8.2(0.2) \\
8.2 \pm 0.0\end{array}$ & $\begin{array}{l}7.8 \\
7.8(0.2) \\
7.7(-0.8) \\
7.8(0.0) \\
7.7(-1.2) \\
7.8 \pm 0.1\end{array}$ & $\begin{array}{l}111 \\
113 \\
114 \\
114 \\
114 \\
114 \pm 0.5\end{array}$ & $\begin{array}{l}83 \\
88 \\
93 \\
90 \\
94 \\
91.0 \pm 2.7\end{array}$ & $\begin{array}{l}100 \\
100 \\
100 \\
100 \\
100 \\
100 \pm 0\end{array}$ & $\begin{array}{l}12.9 \\
14.2 \\
13.9 \\
14.1 \\
14.3 \\
14.1 \pm 0.2\end{array}$ & $\begin{array}{l}1.8 \\
1.9 \\
1.9 \\
2.0 \\
1.9 \\
1.9 \pm 0.1\end{array}$ & $\begin{array}{l}1.3 \\
1.3 \\
1.4 \\
1.3 \\
1.3 \\
1.3 \pm 0.1\end{array}$ & $\begin{array}{l}0.5 \\
0.5 \\
0.5 \\
0.5 \\
0.5 \\
0.5 \pm 0.0\end{array}$ \\
\hline $\begin{array}{l}\text { Patient } 2 \\
\quad \text { (3 fractions) }\end{array}$ & $\begin{array}{l}\text { Planned } \\
\text { Fraction } 1 \\
\text { Fraction } 2 \\
\text { Fraction } 3 \\
\text { Average } \pm 1 \text { SD }\end{array}$ & $\begin{array}{l}24.5 \\
30.0 \\
29.5 \\
24.6 \\
28.0 \pm 3.0\end{array}$ & $\begin{array}{l}20.5 \\
20.3(-1.0) \\
20.2(-1.4) \\
20.2(-1.5) \\
20.2 \pm 0.1\end{array}$ & $\begin{array}{l}19.7 \\
18.8(-4.8) \\
18.2(-7.8) \\
18.2(-7.6) \\
18.4 \pm 0.3\end{array}$ & $\begin{array}{l}117 \\
118 \\
117 \\
117 \\
117 \pm 0.5\end{array}$ & $\begin{array}{l}97 \\
91 \\
91 \\
88 \\
89.6 \pm 1.8\end{array}$ & $\begin{array}{l}100 \\
100 \\
100 \\
99 \\
99.5 \pm 0.3\end{array}$ & $\begin{array}{l}9.7 \\
9.0 \\
8.6 \\
9.6 \\
9.1 \pm 0.5\end{array}$ & $\begin{array}{l}4.7 \\
5.0 \\
5.0 \\
5.1 \\
5.0 \pm 0.0\end{array}$ & $\begin{array}{l}0.4 \\
0.3 \\
0.2 \\
0.3 \\
0.2 \pm 0.0\end{array}$ & $\begin{array}{l}2.9 \\
2.9 \\
2.8 \\
2.7 \\
2.8 \pm 0.1\end{array}$ \\
\hline $\begin{array}{l}\text { Patient } 3 \\
\quad \text { (8 fractions) }\end{array}$ & $\begin{array}{l}\text { Planned } \\
\text { Fraction } 3 \\
\text { Fraction } 4 \\
\text { Average } \pm 1 S D\end{array}$ & $\begin{array}{l}6.8 \\
6.8 \\
5.4 \\
6.1 \pm 1.0\end{array}$ & $\begin{array}{l}8.7 \\
8.9(3.0) \\
8.8(1.5) \\
8.8 \pm 0.1\end{array}$ & $\begin{array}{l}8.3 \\
8.6(2.8) \\
8.2(-2.2) \\
8.4 \pm 0.3\end{array}$ & $\begin{array}{l}117 \\
123 \\
124 \\
123 \pm 0.9\end{array}$ & $\begin{array}{l}100 \\
100 \\
100 \\
100 \pm 0\end{array}$ & $\begin{array}{l}100 \\
100 \\
100 \\
100 \pm 0\end{array}$ & $\begin{array}{l}8.3 \\
8.5 \\
9.7 \\
9.1 \pm 0.8\end{array}$ & $\begin{array}{l}5.7 \\
5.8 \\
5.5 \\
5.6 \pm 0.2\end{array}$ & $\begin{array}{l}0.2 \\
0.2 \\
0.2 \\
0.2 \pm 0.0\end{array}$ & $\begin{array}{l}0.4 \\
0.3 \\
0.3 \\
0.3 \pm 0.0\end{array}$ \\
\hline $\begin{array}{l}\text { Patient } 4 \\
\quad \text { (8 fractions) }\end{array}$ & $\begin{array}{l}\text { Planned } \\
\text { Fraction } 2\end{array}$ & $\begin{array}{l}11.6 \\
11.7\end{array}$ & $\begin{array}{l}8.0 \\
7.9(-1.3)\end{array}$ & $\begin{array}{l}7.8 \\
7.5(-3.5)\end{array}$ & $\begin{array}{l}109 \\
112\end{array}$ & $\begin{array}{l}86 \\
93\end{array}$ & $\begin{array}{l}100 \\
100\end{array}$ & $\begin{array}{l}18.6 \\
19.2\end{array}$ & $\begin{array}{l}1.0 \\
1.0\end{array}$ & $\begin{array}{l}3.0 \\
2.6\end{array}$ & $\begin{array}{l}2.7 \\
2.5\end{array}$ \\
\hline
\end{tabular}


Fraction 3

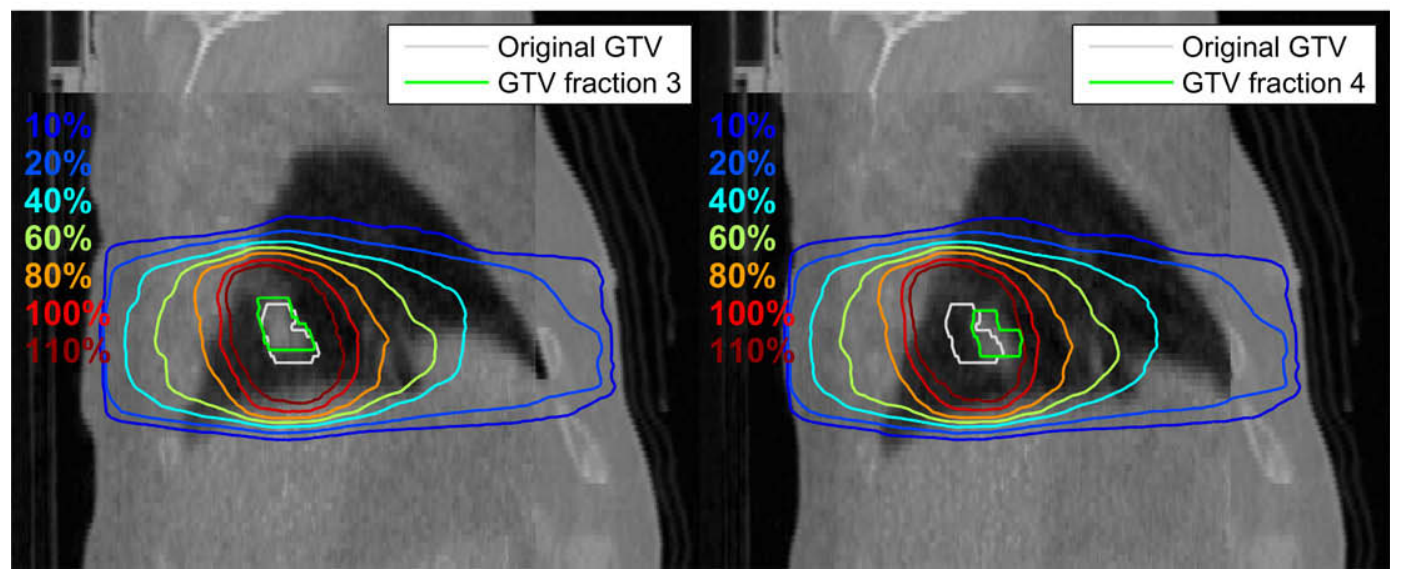

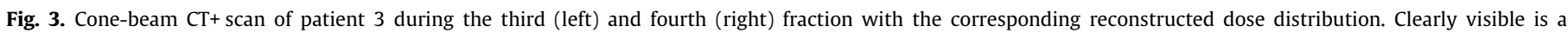
displacement of the GTV in fraction 4 compared to the delineation of the GTV in the planning CT scan. However, the GTV still remains inside the high dose region.

the planned dose. The difference in $V_{20}$ was $0.3 \pm 0.1 \%$. For patients 1,2 and 4 , the gamma analyses yielded good agreement between the planned and reconstructed dose distributions. This was expected, because for these patients only small changes in anatomy were observed compared to the planning CT scan. For patient 3 a shift of the tumour in the posterior-anterior direction was observed leading to a dose difference and deviations in tumour dose.

The use of information acquired during or prior to a treatment session has multiple advantages for dose verification compared to using information derived during the planning phase.

First, the patient anatomy at the day of treatment is imaged with an in-room image-guided radiotherapy technique; in our study MV cone-beam CT imaging. The acquisition of the (4D) treatment planning CT scan is typically several days or weeks prior to the first fraction. Changes in patient anatomy may occur in this period. These possible changes are visible in the cone-beam CT scan acquired for the IGRT procedure used for patient set-up. An example is presented in Fig. 3. We used a 3D imaging technique currently available at our institution. With 4D (cone-beam) imaging the accuracy might even be improved and a comprehensive analysis, not only of the anatomy (volumetric) changes, but also of possible changes in breathing frequency or amplitude might be investigated [19].

Second, we implemented an independent dose calculation algorithm based on Monte Carlo calculations. These simulations, if implemented correctly, have in principle the highest accuracy currently available. Especially for the thorax, dose calculation algorithms that take into account density inhomogeneities are preferred and necessary for accurate and reliable dose calculations $[1,2]$. Using inappropriate simple pencil beam algorithms are not sufficient for these treatment sites. When using such algorithms large differences are expected between the reconstructed and planned dose distribution which is then the main source of discrepancy. Using the currently available advanced dose calculation algorithms these differences are minimized [1].

Third, the treatment machine output may differ from the planned delivery by the treatment planning system. A simplified implementation of the treatment machine, for example the multi-leaf collimator, may lead to differences in the delivered and planned dose distribution. Such differences will also show up with the dose reconstruction procedure. Because the energy fluence, delivered by the linear accelerator and measured with the EPID, is used as input for dose reconstruction, possible differences between the planned and delivered fluence are taken into account. Both the absolute output and the relative energy fluence for wedges or intensity-modulated beams are measured and used for the dose reconstruction. The presented method is not limited to SBRT treatments of lung cancer patients but can be used for every treatment schedule or treatment site. The proposed method does not necessarily mean that a pre-treatment QA procedure might become obsolete. Especially for hypo-fractionated treatments, a QA procedure might reveal errors in accurate treatment plan delivery before the first irradiation is performed.

This method differs from previous described methods in the literature. The actual imaging anatomy is used for the dose calculation $[16,20]$. Previous studies also showed the use of the transit or exit dose in combination with in-room imaging data [6,21]. An advantage of transit dosimetry compared to the use of the pretreatment energy fluence is that day-to-day variations in linac output and potential small leaf positioning differences are taken into account. Because these variations are generally within $1 \%$ or less than $1 \mathrm{~mm}$, respectively, no large deviations are expected if the treatment machine behaves within tolerance. For stereotactic lung cancer treatments often couch rotations are used to reduce the volume on healthy lung reaching the normal tissue constraints. Couch rotations may hamper the acquisition of the transit EPID dose images due to collisions of the couch and EPID. In that case transit dosimetry is not possible. Using pre-treatment energy fluence is then the best option.

Several strategies can be used to compare the delivered and planned dose distribution. A direct comparison of the planned the reconstructed dose distribution could be performed by (rigidly) registering the planning CT scan with the repeated CT scan. This method can be automated and provides fast feedback about possible changes between the planned and delivered dose distribution. It can be used without redelineating organs on the cone-beam CT scans. The disadvantage is that the relevance of observed differences, in terms of the dose to the target or healthy structures, is not known. For that purpose a structure-based comparison is needed where the dose delivered to a specific organ or target is compared with the planned dose. This method requires redelineation of the structures and is therefore more time consuming, but it gives a better insight and provides the information needed for plan adaptation and adaptive radiotherapy. Although atlas-based delineations may reduce the amount of normal structures that need to be delineated, at present automatic delineation of the target volume is not available. 
The next step of 3D dose verification is to add up the dose distributions of the various fractions. For this purpose deformable registration algorithms are needed. These algorithms are currently becoming available and are being validated [22,23]. However it is still not clear how to incorporate disappearing voxels (e.g. a shrinking tumour). Moreover, accurate calculation of the deformation inside homogeneous regions without density information is challenging. These techniques will be used in the future to determine the actual dose delivered to every voxel. This is needed to study recurrence and treatment response of the tumour [24], but also for estimating the dose in the normal tissues. Information about the variation in dose in each voxel for a specific treatment is valuable input for uncertainty based planning strategies [25]. The procedure and results presented in this work provide the input for these dose accumulation algorithms to determine the cumulative dose delivered to a patient during the entire course of treatment.

\section{Conclusion}

A 3D dose reconstruction procedure was developed for lung cancer patients treated with SBRT using an independent Monte Carlo based 3D dose calculation. The 3D dose distribution is determined inside the patient anatomy at the day of treatment using inroom MV cone-beam CT based on the actual delivered fields by the linear accelerator as measured prior to treatment using an EPID. Treatment verification for SBRT of lung cancer patients is feasible and provides information about the dose delivered in 3D.

\section{Acknowledgement}

We would like to thank Siemens OCS for technical and financial support.

\section{References}

[1] Knoos T, Wieslander E, Cozzi L, et al. Comparison of dose calculation algorithms for treatment planning in external photon beam therapy for clinical situations. Phys Med Biol 2006;51:5785-807.

[2] N, Battista J, Boyer A et al. Tissue inhomogeneity corrections for megavoltage photon beams. AAPM report 85, Task Group No. 65 of the Radiation Therapy Committee of the American Association of Physicists in Medicine. Madison, WI: Medical Physics Publishing; 2004.

[3] Dawson LA, Jaffray DA. Advances in image-guided radiation therapy. J Clin Oncol 2007;25:938-46.

[4] Verellen D, Ridder MD, Linthout N, Tournel K, Soete G, Storme G. Innovations in image-guided radiotherapy. Nat Rev Cancer 2007;7:949-60.

[5] van Elmpt W, McDermott L, Nijsten S, Wendling M, Lambin P, Mijnheer B. A literature review of electronic portal imaging for radiotherapy dosimetry. Radiother Oncol 2008:88:289-309.
[6] McDermott LN, Wendling M, Nijkamp J, et al. 3D in vivo dose verification of entire hypo-fractionated IMRT treatments using an EPID and cone-beam CT. Radiother Oncol 2008;86:35-42.

[7] van Zijtveld M, Dirkx M, Heijmen B. Correction of conebeam CT values using a planning CT for derivation of the "dose of the day". Radiother Oncol 2007;85:195-200.

[8] van Zijtveld M, Dirkx ML, de Boer HC, Heijmen BJ. 3D dose reconstruction for clinical evaluation of IMRT pretreatment verification with an EPID. Radiother Oncol 2007;82:201-7.

[9] Ding GX, Duggan DM, Coffey CW, et al. A study on adaptive IMRT treatment planning using kV cone-beam CT. Radiother Oncol 2007;85:116-25.

[10] Nijsten SM, van Elmpt WJ, Jacobs M, et al. A global calibration model for a-Si EPIDs used for transit dosimetry. Med Phys 2007;34:3872-84.

[11] Hurkmans CW, Cuijpers JP, Lagerwaard FJ, et al. Recommendations for implementing stereotactic radiotherapy in peripheral stage IA non-small cell lung cancer: report from the Quality Assurance Working Party of the randomised phase III ROSEL study. Radiat Oncol 2009;4:1.

[12] Petit SF, van Elmpt WJ, Nijsten SM, Lambin P, Dekker AL. Calibration of megavoltage cone-beam CT for radiotherapy dose calculations: correction of cupping artifacts and conversion of CT numbers to electron density. Med Phys 2008;35:849-65.

[13] Morin O, Chen J, Aubin M, et al. Dose calculation using megavoltage conebeam CT. Int J Radiat Oncol Biol Phys 2007;67:1201-10.

[14] Aubry JF, Cheung J, Morin O, Gottschalk A, Beaulieu L, Pouliot J, et al. J Appl Clin Med Phys 2009;10:2852.

[15] Petit S, van Elmpt W, Lambin P, Dekker A. Dose recalculation in megavoltage cone-beam CT for treatment evaluation: removal of cupping and truncation artefacts in scans of the thorax and abdomen. Radiother Oncol 2010. doi:10.1016/i.radonc.2009.12.001.

[16] van Elmpt W, Nijsten S, Mijnheer B, Dekker A, Lambin P. The next step in patient-specific QA: 3D dose verification of conformal and intensitymodulated RT based on EPID dosimetry and Monte Carlo dose calculations. Radiother Oncol 2008;86:86-92.

[17] van Elmpt WJ, Nijsten SM, Dekker AL, Mijnheer BJ, Lambin P. Treatment verification in the presence of inhomogeneities using EPID-based threedimensional dose reconstruction. Med Phys 2007;34:2816-26.

[18] van Elmpt WJ, Nijsten SM, Schiffeleers RF, et al. A Monte Carlo based threedimensional dose reconstruction method derived from portal dose images. Med Phys 2006;33:2426-34.

[19] Sonke JJ, Lebesque J, van Herk M. Variability of four-dimensional computed tomography patient models. Int J Radiat Oncol Biol Phys 2008;70:590-8.

[20] Wendling M, McDermott LN, Mans A, Sonke JJ, van Herk M, Mijnheer BJ. A simple backprojection algorithm for 3D in vivo EPID dosimetry of IMRT treatments. Med Phys 2009;36:3310-21.

[21] van Elmpt W, Nijsten S, Petit S, Mijnheer B, Lambin P, Dekker A. 3D in vivo dosimetry using megavoltage cone-beam CT and EPID dosimetry. Int J Radia Oncol Biol Phys 2009;73:1580-7.

[22] Janssens G, de Xivry JO, Fekkes S, et al. Evaluation of nonrigid registration models for interfraction dose accumulation in radiotherapy. Med Phys 2009;36:4268-76

[23] Zhang GG, Huang TC, Forster KM, et al. Dose mapping: validation in 4D dosimetry with measurements and application in radiotherapy follow-up evaluation. Comput Methods Programs Biomed 2008;90:25-37.

[24] Petit SF, Aerts HJ, van Loon JG, et al Metabolic control probability in tumour subvolumes or how to guide tumour dose redistribution in non-small cel lung cancer (NSCLC): an exploratory clinical study. Radiother Oncol 2009;91:393-8.

[25] Witte MG, Van der Geer J, Schneider C, Lebesque JV, Alber M, van Herk M. IMRT optimization including random and systematic geometric errors based on the expectation of TCP and NTCP. Med Phys 2007;34:3544-55 